\title{
10th International Psychiatric Conference on Mental Health in Developing Countries*
}

\author{
M. Riaz Bhatti, M. Sharif Chaudry and M. F. Hussain
}

In December 1994 Lahore was host to an international psychiatric conference with participants from various countries including Pakistan, UK, France, Denmark, Belgium, Germany, Kuwait, Qatar, Saudi Arabia, Belarus, USA, Canada and Australia. The main contingent of foreign delegates of about 40 consultants was from the UK.

For developing countries like Pakistan, bearing in mind per capita income and restraints on drug budgets, psychological methods of treatment are a welcome option. In a debate 'Psychotherapy v. Psychopharmacotherapy for the Mental Health Care of the Developing Countries', linked by satellite with an associate professor in Kansas, Professor Eve Johnstone (Edinburgh) spoke in favour of psychopharmacotherapy and Professor M. G. Gelder (Oxford) defended psychotherapy. The house decided that a combination of both treatments was the appropriate option.

UK delegates learnt about the history and development of psychiatric services in Pakistan, the standard of the practice and teaching of psychiatry in this country and gained knowledge of the potential trainees in psychiatry for whom the ODTS (Overseas Doctors Training Scheme) under the auspices of the College is already in place. Undergraduate training in psychiatry and students' participation has been encouraged by the regular award of a Gold Medal for undergraduate students who compete for them at each of these conferences where they

"Held at Lahore in December 1994. have to pass an MCQ and appear in a viva voce. This time the head of the jury was Professor Gelder who commented that, "the standard of medical students was no less than any European country for its psychiatric teaching". There was also an award for best original research and for an essay on the theme of the conference.

It was an occasion to renew acquaintances and to take stock of teaching methods and clinical experiences along with the examination standard of local diplomas in psychiatry in Pakistan. Future needs were also discussed such as keeping abreast of new psychopharmacological agents, research methodology, transcultural studies, and coping with rising numbers of the psychiatrically ill.

The historical city of Lahore, its castle, Mughal tombs and architecture, the Shalimar garden, hustle and bustle of bazaars, Kim's gun (memory of Rudyard Kipling), call for prayers from minarets, and colourful costumes, the contrast in economic status of Pakistanis, was like looking into a kaleidoscope, with different presenting patterns. It was an enjoyable, informative and commemorative occasion.

The next International Conference will be held at Karachi in December 1996.

M. Riaz Bhatti, Associate Professor, Department of Psychiatry, Lahore, Pakistan; M. Sharif Chaudry, Professor and Head, Department of Psychiatry, Allama Iqbal Medical College, Lahore, Pakistan; and M. F. Hussain, Canterbury, Kent 